\title{
Estimating the Harms of Nicotine-Containing Products Using the MCDA Approach
}

\author{
David J. Nutt ${ }^{a} \quad$ Lawrence D. Phillips $^{b}$ David Balfour ${ }^{f} \quad H$. Valerie Curran $^{c}$ \\ Martin Dockrell ${ }^{\mathrm{d}}$ Jonathan Foulds ${ }^{\mathrm{h}}$ Karl Fagerstrom $^{\mathrm{i}}$ Kgosi Letlape $^{\mathrm{k}}$ \\ Anders Milton ${ }^{j}$ Riccardo Polosal John Ramsey ${ }^{\mathrm{e}}$ David Sweanorg \\ ${ }^{a}$ Imperial College London, UK; ${ }^{b}$ Department of Management, London School of Economics and Political \\ Science, and Facilitations Ltd., UK; ' ${ }^{\mathrm{C}}$ University College London, UK; ${ }^{\mathrm{d}}$ Action on Smoking and Health London,

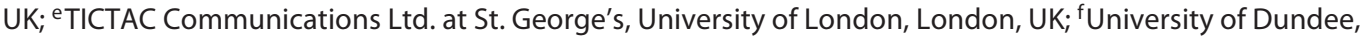

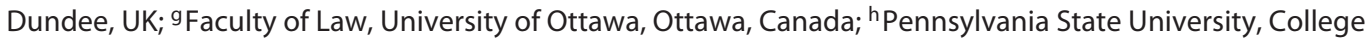 \\ of Medicine, Hershey Pa., USA; ${ }^{i}$ Fagerström Consulting, Vaxholm, Sweden; ${ }^{j}$ World Medical Association, Milton \\ Consulting, Stockholm, Sweden; ${ }^{k}$ World Medical Association, Johannesburg, South Africa; 'Centre for the \\ Prevention and Cure of Tobacco Use, University of Catania, Catania, Italy
}

\section{Key Words}

Smoked tobacco products - Oral tobacco products. Electronic cigarettes - Multi criteria decision analysis . Harm assessment - ENDS (electronic nicotine delivery systems)

\begin{abstract}
Background: An international expert panel convened by the Independent Scientific Committee on Drugs developed a multi-criteria decision analysis model of the relative importance of different types of harm related to the use of nicotine-containing products. Method: The group defined 12 products and 14 harm criteria. Seven criteria represented harms to the user, and the other seven indicated harms to others. The group scored all the products on each criterion for their average harm worldwide using a scale with 100 defined as the most harmful product on a given criterion, and a score of zero defined as no harm. The group also assessed relative weights for all the criteria to indicate their relative importance. Findings: Weighted averages of the scores pro-
\end{abstract}

vided a single, overall score for each product. Cigarettes (overall weighted score of 100) emerged as the most harmful product, with small cigars in second place (overall weighted score of 64). After a substantial gap to the third-place product, pipes (scoring 21), all remaining products scored 15 points or less. Interpretation: Cigarettes are the nicotine product causing by far the most harm to users and others in the world today. Attempts to switch to non-combusted sources of nicotine should be encouraged as the harms from these products are much lower.

(c) 2014 S. Karger AG, Basel

\section{Introduction}

The recreational use of tobacco remains one of the principal causes of chronic ill health and early death worldwide. The tobacco epidemic was largely reflected in more affluent Western countries but, increasingly, the illnesses associated with tobacco use have spread to the developing world [1]. Cigarettes are considered to be the most harm-

\begin{tabular}{ll}
\hline KARGER & $\begin{array}{l}\text { () 2014 S. Karger AG, Basel } \\
1022-6877 / 14 / 0205-0218 \$ 39.50 / 0 \quad \text { Karger }\end{array}$ \\
$\begin{array}{l}\text { E-Mail karger@karger.com } \\
\text { www.karger.com/ear }\end{array}$ & $\begin{array}{l}\text { This is an Open Access article licensed under the terms of the } \\
\text { Creative Commons Attribution-NonCommercial 3.0 Un- } \\
\text { ported license (CC BY-NC) (www.karger.com/OA-license), } \\
\text { applicable to the online version of the article only. Distribu- } \\
\text { tion permitted for non-commercial purposes only. }\end{array}$
\end{tabular}

David Nut

Imperial College London

Burlington Danes Building

London W12 ONN (UK)

E-Mail d.nutt@imperial.ac.uk 
ful tobacco product although other forms of tobacco used recreationally may also result in harm to the user [2].

It is now widely accepted that the compulsive use of tobacco reflects the development of dependence upon the nicotine present in tobacco and many of the pharmacological interventions that are employed to aid smoking cessation target this dependence $[3,4]$. However, in experimental animals, nicotine does not have the potent addictive properties that are required to explain the powerful addiction to tobacco experienced by many habitual smokers $[5,6]$. Thus, it has been proposed that other pharmacologically active substances present in tobacco smoke and the conditioned sensory stimulation associated with inhaling tobacco smoke have a significant role in the development of dependence upon tobacco [7-10]. Pharmacological nicotine replacement products (NRT) were introduced as aids to smoking cessation in the late 1970s and continue to be used extensively in the treatment of tobacco dependence. Experience with these preparations suggests that their use is not associated with an increased risk of chronic obstructive pulmonary disease, lung cancer or cardiovascular disease $[3,11]$ although there are reports that nicotine may be metabolized to compounds that are potentially carcinogenic $[12,13]$. Furthermore, studies with experimental animals suggest that the ingestion of nicotine during pregnancy can have adverse effects on the brain development of the fetus and the vulnerability of the progeny to nicotine dependence $[14,15]$. Relatively little direct information is available for the effects of maternal nicotine on human development and behaviour. However, smokeless tobacco has been found to have a negative effect [16] and Bruin et al. [17] have argued that the possibility of adverse effects for both the mother and fetus of NRT use during pregnancy should not be disregarded. Thus, individual researchers have expressed differing opinions on the safety of pharmacological nicotine. Nevertheless, some 40 years' experience with NRT preparations suggest that they are safe and are not associated with significant adverse medical consequences [4]. This conclusion is consistent with the compelling evidence that many of the adverse health effects of inhaling tobacco smoke are caused by other components of the smoke such as nitrosamines, carbon monoxide and nitric oxide $[18,19]$. Thus, despite some differences in opinion, it seems that tobacco use lends itself rather better than many other forms of addiction to a harm reduction approach using pharmacological interventions including therapeutic nicotine preparations.

Most attention with regard to the harmful effects of tobacco use has focused on cigarettes and the evidence that they cause chronic illness and early death is compelling.
However, other forms of tobacco use also need to be considered. There is good evidence, for example, that Swedish snus, a form of refined oral tobacco which is low in nitrosamines, is at worst only weakly associated with an increased risk of cancer or cardiovascular disease [20]. By contrast, other smokeless unrefined oral tobacco products seem to be associated with significantly more harm to the user [21]. For example, the chronic use of gutkha, a form of smokeless tobacco popular with members of the Asian community, is associated with the development of disorders of the oral mucosa and oral cancer [22]. Water pipes, widely used in the Middle East, are finding increasing favour in Western society. The potential toxic effects of water pipe smoke have not yet been fully evaluated although some concerns have been expressed about the potential adverse consequences for health of using this form of tobacco $[23,24]$. Our understanding of the potential hazards associated with using electronic nicotine delivery systems (ENDS, e.g. E-cigarettes) is at a very early stage. These delivery systems are seen as an acceptable form of recreational nicotine use with a minimal potential for second-hand environmental contamination. Nevertheless, there is concern that these devices should not be introduced in an unregulated way until potential associated harms are adequately evaluated [25].

There remains a need for policy makers to become better informed of the relative harms of nicotine delivery systems in order to build a regulatory framework that minimizes harm. The aim of the current study was to convene a group of experts with expertise in the field of nicotine and tobacco research from different disciplines (animal and behavioural pharmacology, toxicology, medicine, psychiatry, policy and law) that could discuss and agree on the harmfulness of nicotine-containing products using a multi-criteria decision analysis (MCDA) model and, thus, provide a sound framework within which policy makers might work.

\section{Methods}

Study Design

The Independent Scientific Committee on Drugs selected experts from several different countries to ensure a diversity of expertise and perspective, as evident from the author list. The MCDA process [26] was conducted during a 2-day facilitated workshop held in London in July 2013. The MCDA model for the harm of psychoactive drugs developed by the Independent Scientific Committee on Drugs in 2010 [27] provided a starting point for this nicotine harm study, as it covered all the potential parameters of harm that might potentially be caused by any drug.

The MCDA process is a way to compare variables of harm in widely different areas where traditional metrics are not available. It works through a series of eight stages: (1) establishing context; 
(2) agreeing on the products to be evaluated and producing definitions of these; (3) agreeing on the criteria on which the products were to be compared; (4) scoring the products on each criterion; (5) weighting the criteria; (6) calculating weighted scores to give an overall index of the harm of each product; (7) examining results and resolving any inconsistencies, and (8) exploring the sensitivity of the indices to different assessments of scores and weights.

\section{The Context}

The group recognized that there are regional and national differences in actual and perceived harm of nicotine products, so participants agreed to take a worldwide perspective and consider average harm.

\section{The Nicotine Products}

After considering many nicotine products and the criteria for comparing the products, the group discussed steps 2 and 3 above in a reciprocal and iterative way so that the final set of products was substantially different from one another in important ways. Table 1 gives the final agreement about the products and their definitions.

\section{The Criteria of Harms}

The group reviewed the 16 criteria that had first been agreed by the UK Advisory Council on the Misuse of Drugs [28] and used by the Independent Scientific Committee on Drugs in their 2010 decision conference on 20 psychoactive drugs [27]. All but two criteria were retained but where necessary were redefined to be relevant to nicotine products. The two that were dropped were drug-specific and drug-related mental impairment as it was thought that there was little evidence for these with any of the nicotine products.

The criteria against which the products were evaluated are shown at the extreme right of the harm tree in figure 1 . The main objective was to determine an ordering of the products at the 'Product harms' node. The next level to the right provides separate harm groupings of the criteria: 'To users' (harm to those who are using the product) and 'To others' (harm as a consequence of the use of the product to others both directly and indirectly). Assessments of the harms for all products were made against the criteria given at the extreme right of the value tree. The final definitions are shown in table 2 .

\section{Scoring the Products}

The group scored all products on all criteria. The scoring system used points out of 100 , with 100 assigned to the most harmful product on a given criterion and zero representing 'no harm'.

In scaling the products, care is required to ensure that each successive point on the scale represents equal increments of harm. Thus, if a product is scored at 50 , then it should be half as harmful as the product scored 100. Because zero represents no harm, this scale can be considered a ratio scale, which makes possible ratio comparisons of the weighted scales.

\section{Weighting}

Some criteria are more important expressions of harm than others, so weighting of the criteria is required. 'Swing weighting' provides weights that are meaningful in MCDA. As an analogy, both Fahrenheit and Celsius scales contain $0-100$ portions, but the swing in temperature from 0 to 100 on the Fahrenheit scale is, of course, a smaller swing in temperature than $0-100$ on a Celsius scale; it takes 5 Celsius units to equal 9 Fahrenheit units. The purpose of weighting is to ensure that the units of harm on the different harm scales are equivalent, thus enabling weighted scores to be compared and combined across the criteria. Weights are scale factors.

To assess scale factors two steps in thinking must be separated. First, it is necessary to think about the difference in harm between the most and least harmful products on that criterion. The next step is to think about how much that difference in harm matters in a given context. 'How big is the difference in harm and how much do you care about that difference?' This is the question that was posed in comparing the 0 -to- 100 swing in harm on one scale with the 0 -to- 100 swing on another scale, assuming the harm is a worldwide average.

Swing weights for the User criterion were assessed first; the largest swing, on Product-specific morbidity, the difference between cigarettes and nasal sprays was assigned a weight of 100 . Next, weights were judged for the criteria at the Other node: the largest swing, the difference between cigarettes and small cigars for Economic cost, was set at 100. Finally, those two 100's were compared by judging their swing weights. The swing for Product-re-

Table 1. The 12 products considered during the decision conference and their definitions

\begin{tabular}{|c|c|}
\hline Cigarettes & $\begin{array}{l}\text { manufactured and hand-rolled cigarettes in which } \\
\text { the tobacco is wrapped in paper }\end{array}$ \\
\hline Cigars & $\begin{array}{l}\text { smoked cigars: roll of tobacco wrapped in tobacco } \\
\text { leaf }\end{array}$ \\
\hline $\begin{array}{l}\text { Little and } \\
\text { small cigars }\end{array}$ & $\begin{array}{l}\text { used like a cigarette wrapped in tobacco leaf, } \\
\text { sometimes with a filter (a product that has } \\
\text { emerged in response to the US tobacco taxation } \\
\text { system and would, in most jurisdictions be } \\
\text { considered cigarettes) }\end{array}$ \\
\hline Pipes & $\begin{array}{l}\text { a tube with a small bowl at one end for smoking } \\
\text { tobacco }\end{array}$ \\
\hline Water pipe & $\begin{array}{l}\text { a pipe where tobacco smoke is bubbled through } \\
\text { water }\end{array}$ \\
\hline $\begin{array}{l}\text { Smokeless } \\
\text { refined }\end{array}$ & $\begin{array}{l}\text { non-snus (and other) smokeless refined tobacco } \\
\text { products used orally, including moist chewing } \\
\text { tobacco and snuff (common in USA) }\end{array}$ \\
\hline $\begin{array}{l}\text { Smokeless } \\
\text { unrefined }\end{array}$ & $\begin{array}{l}\text { non-snus (and other) smokeless unrefined } \\
\text { tobacco products used orally, including chewing } \\
\text { tobacco and dry snuff (products common in SE } \\
\text { Asia) }\end{array}$ \\
\hline Snus & $\begin{array}{l}\text { a low nitrosamine and non-fermented smokeless } \\
\text { tobacco product (popular in Scandinavia and now } \\
\text { in USA) }\end{array}$ \\
\hline ENDS & $\begin{array}{l}\text { electronic nicotine delivery system products, } \\
\text { e.g. e-cigs (electronic cigarettes either cigarette- } \\
\text { like or personal vaporizers) }\end{array}$ \\
\hline $\begin{array}{l}\text { Oral } \\
\text { products }\end{array}$ & $\begin{array}{l}\text { oral nicotine delivery products (including NRT } \\
\text { products) }\end{array}$ \\
\hline Patch & dermal nicotine delivery products \\
\hline Nasal sprays & nasal nicotine delivery products \\
\hline
\end{tabular}


Fig. 1. Evaluation criteria organized by harms to users and harms to others.

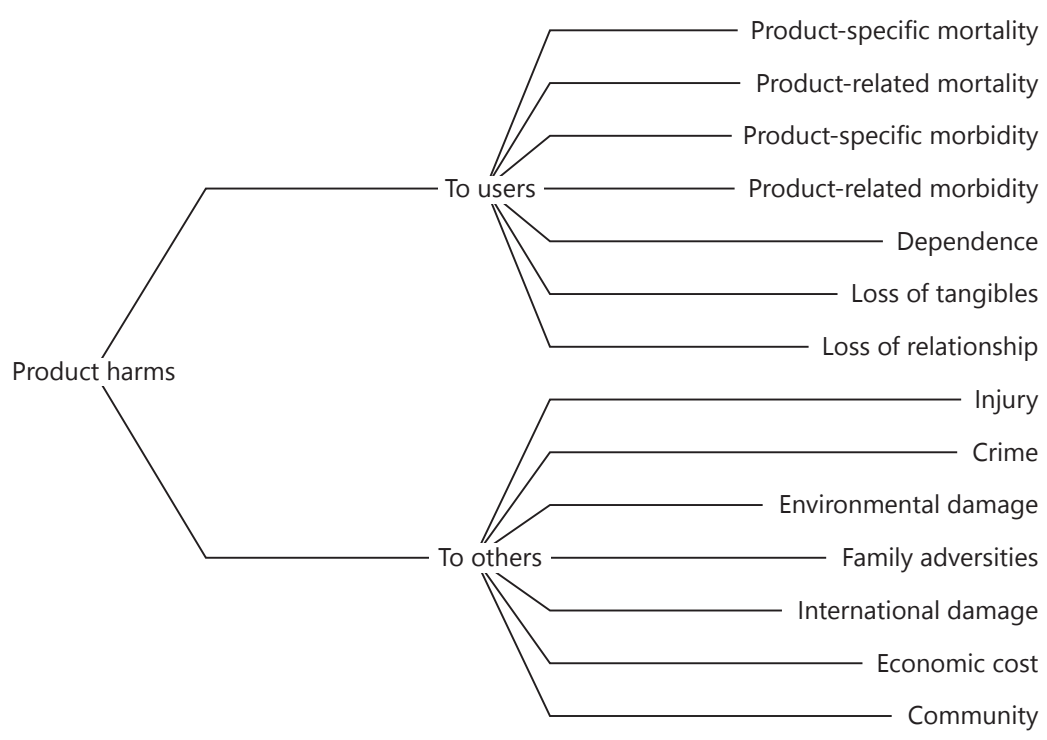

Table 2. Definitions of the evaluation criteria for the nicotine products

\begin{tabular}{|c|c|}
\hline Name & Description \\
\hline $\begin{array}{l}\text { Product-specific } \\
\text { mortality }\end{array}$ & deaths directly attributed to product misuse or abuse as in the case of accidental and deliberate poisoning \\
\hline $\begin{array}{l}\text { Product-related } \\
\text { mortality }\end{array}$ & deaths indirectly attributed to the product, e.g. death due to cancer, respiratory illness, cardiovascular disease and fire \\
\hline $\begin{array}{l}\text { Product-specific } \\
\text { morbidity }\end{array}$ & $\begin{array}{l}\text { damage (morbidity, chronic ill health) to physical health directly attributed to product misuse or abuse, e.g. ulcers, } \\
\text { lung disease, heart disease }\end{array}$ \\
\hline $\begin{array}{l}\text { Product-related } \\
\text { morbidity }\end{array}$ & damage to physical health indirectly attributed to product misuse or abuse, e.g. burns, allergies \\
\hline Dependence & $\begin{array}{l}\text { extent to which the product creates a propensity or urge to continue use despite adverse consequences and causes } \\
\text { withdrawal symptoms on cessation }\end{array}$ \\
\hline Loss of tangibles & extent of loss of tangible things (e.g. income, housing, job) \\
\hline Loss of relationships & extent of loss of relationships with family and friends \\
\hline Injury & $\begin{array}{l}\text { the extent to which the product increases chances of injuries to others both directly and indirectly, e.g. traffic accident, } \\
\text { fetal harm, second-hand smoke, accidental poisoning, burns }\end{array}$ \\
\hline Crime & $\begin{array}{l}\text { the extent to which the use of the product increases criminal behaviour (e.g. smuggling) directly or indirectly (at the } \\
\text { population level, not the individual) }\end{array}$ \\
\hline $\begin{array}{l}\text { Environmental } \\
\text { damage }\end{array}$ & $\begin{array}{l}\text { the extent to which the use and production of this product causes environmental damage locally, e.g. fires, competition } \\
\text { for arable land, cigarette stub pollution }\end{array}$ \\
\hline Family adversities & the extent to which the use of the product causes family adversities, e.g. economic well-being, future prospects of children \\
\hline $\begin{array}{l}\text { International } \\
\text { damage }\end{array}$ & $\begin{array}{l}\text { the extent to which the use of the product contributes to damage at an international level, e.g. deforestation, } \\
\text { contraband as criminal activity, counterfeiting }\end{array}$ \\
\hline Economic cost & $\begin{array}{l}\text { the extent to which the use of the product results in effects that create direct costs to countries (e.g. health-care costs, } \\
\text { customs) and indirect costs (e.g. loss of productivity, absenteeism) }\end{array}$ \\
\hline omm & \\
\hline
\end{tabular}




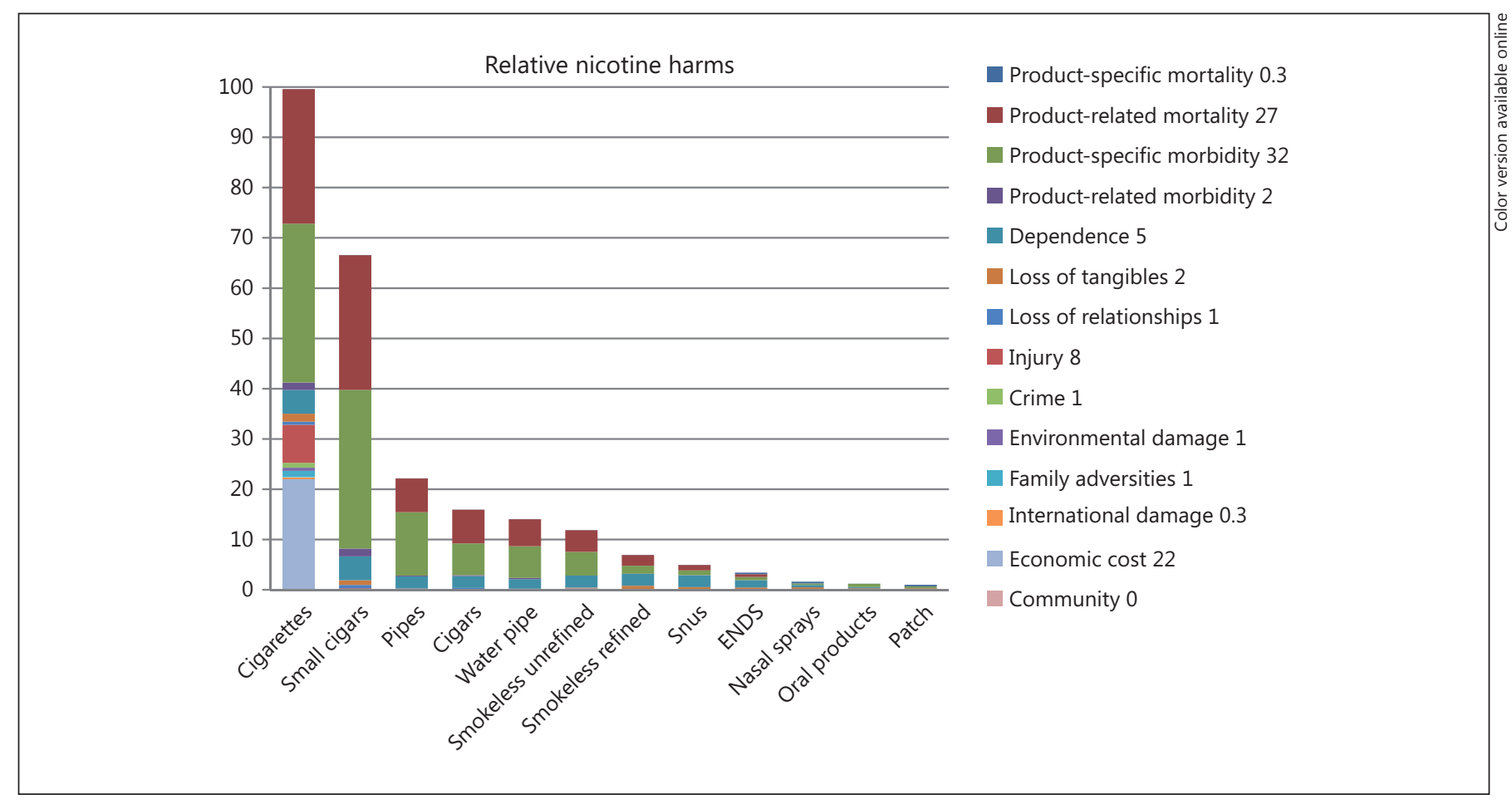

Fig. 2. Overall weighted scores for each of the products. Cigarettes, with an overall harm score of 99.6, are judged to be most harmful, and followed by small cigars at 67 . The heights of the coloured portions indicate the part scores on each of the criteria. Product-related mortality, the upper dark red sections, are substantial contribu- tors to those two products, and they also contribute moderately to cigars, pipes, water pipes, and smokeless unrefined. The numbers in the legend show the normalized weights on the criteria. Higher weights mean larger differences that matter between most and least harmful products on each criterion. lated morbidity was weighted as the larger harm that matters, so its weight of 100 was retained. The swing for Economic cost was assessed as $70 \%$ of that, so the original weights for all the Economic criteria were multiplied by 0.70 .

As scores and weights were agreed, they were input to the Hiview computer program ${ }^{1}$, which normalized the weights so they summed to 100 , calculated the weighted scores and displayed the results.

\section{Results}

Figure 2 shows the overall weighted scores of the nicotine products as stacked bar graphs. Cigarettes and small cigars are each several times more harmful than any of the other products. Similarly coloured sections of the bar graphs show a given criterion's weighted harm value as it contributes to the overall weighted scores of the nicotine products. Thus, Product-related mortality and Product-

\footnotetext{
${ }^{1}$ An MCDA computer program first developed at the London School of Economics and Political Science and now available from Catalyze Ltd., www. catalyze.co.uk.
}

specific morbidity are the main harms for cigarettes and small cigars, while Economic cost is also a substantial contributor to the overall harm for cigarettes.

The stacked bar graphs can also be shown for their separate contributions of harm 'To users' and harm 'To others'. Figure 3 gives the harm to users as the blue section, and harm to others as red. Harm to others makes a substantial contribution only to cigarettes, and virtually none to the other 11 products.

Why are cigarettes considered the most harmful? Figure 4 shows the contribution that each criterion makes to cigarettes' total weighted score. Each row in the display gives the part-score for that criterion (Wtd Diff), and it is the sum of those part scores that gives the overall score of 99.6. These part-scores determine the relative heights of each of the coloured bands for the cigarettes' bar graph in figure 4 . Note that cigarettes were assigned harm scores of 100 on 12 of the 14 criteria, but that just five of those 14 collectively contribute a score of 92.7, nearly as much as the total of 99.6 .

Both cigarettes and small cigars score 100 on three of the most important criteria: Product-specific morbidi- 
Fig. 3. The products ordered by their overall harm scores, with the stacked bar graphs showing the contribution to the overall score of harms to users and harm to others. The numbers in the legend show the sums of the normalized weights at each node.

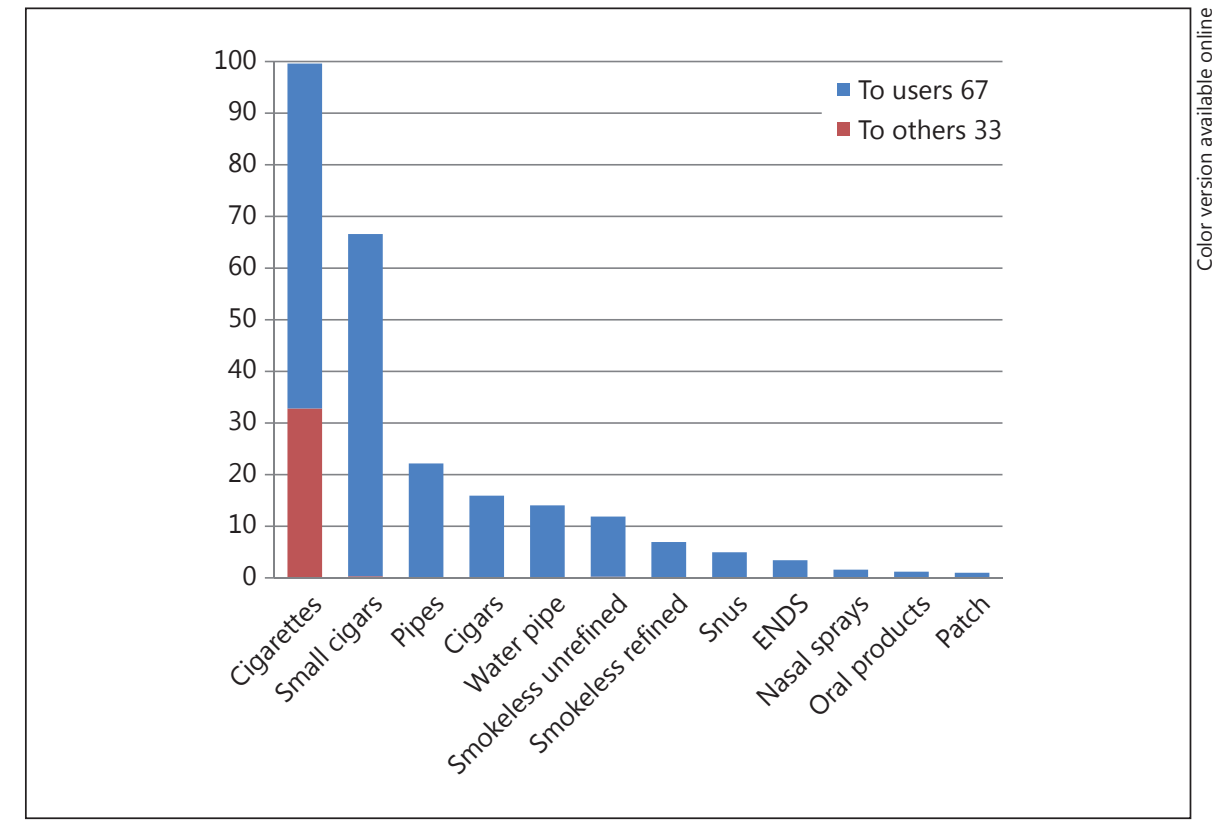

Fig. 4. The relative harms of cigarettes. The cumulative weight (Cum Wt) column shows the normalized weight for each criterion. The harm score for cigarettes, shown in the Diff column, on each criterion is multiplied by the cumulative weight of the corresponding criterion to give a weighted score (i.e., a part-score), shown in the Wtd Diff column. The lengths of the green bars are proportional to the weighted scores, so the longer the green bars, the more that harm matters for its effects from cigarettes.

\begin{tabular}{|c|c|c|c|c|c|c|}
\hline \multirow[t]{2}{*}{ Compare $\longdiv { \text { Ciga } }$} & \multirow[b]{2}{*}{ Model Order } & \multicolumn{2}{|l|}{ All at 0} & $\nabla$ & \multirow[b]{2}{*}{ Sum } & \\
\hline & & Cum Wt & Diff & Wtd Diff & & \\
\hline TO USERS & Product spec morb & 31.5 & 100 & 31.5 & 31.5 & 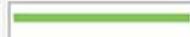 \\
\hline TO USERS & Product rel mort & 26.8 & 100 & 26.8 & 58.4 & $=$ \\
\hline TO OTHERS & Economic cost & 22.1 & 100 & 22.1 & 80.4 & $=$ \\
\hline TO OTHERS & Injury & 7.6 & 100 & 7.6 & 88.0 & $=$ \\
\hline TO USERS & Dependence & 4.7 & 100 & 4.7 & 92.7 & $=$ \\
\hline TO USERS & Loss of tangibles & 1.6 & 100 & 1.6 & 94.3 & " \\
\hline TO USERS & Product rel morb & 1.6 & 95 & 1.5 & 95.8 & - \\
\hline TO OTHERS & Family adversities & 1.3 & 100 & 1.3 & 97.1 & . \\
\hline TO OTHERS & Crime & 0.9 & 100 & 0.9 & 98.0 & , \\
\hline TO USERS & Loss of relationship & 0.6 & 100 & 0.6 & 98.7 & 1 \\
\hline TO OTHERS & Environmental damage & 0.6 & 100 & 0.6 & 99.3 & 1 \\
\hline TO OTHERS & International damage & 0.3 & 100 & 0.3 & 99.6 & ' \\
\hline TO USERS & Product spec mort & 0.3 & 0 & 0.0 & 99.6 & \\
\hline \multirow[t]{2}{*}{ TO OTHERS } & Community & 0.0 & 100 & 0.0 & 99.6 & \\
\hline & & 100.0 & & 99.6 & & \\
\hline
\end{tabular}

ty, Product-related mortality and Dependence. Those three are harms to the users, criteria which do not take account of the extent of usage worldwide. However, cigarettes also score 100 on Economic cost and Injury, which are harms to others that do take account of global usage. It is those two criteria that account for the difference in the total scores of cigarettes compared to small cigars.

Estimating the Harms of Nicotine-Containing Products

\section{Discussion}

Perhaps not surprisingly, given their massively greater use as compared with other products, cigarettes were ranked the most harmful, followed by small cigars as two thirds as harmful. It is only the relative lack of harm to others that positioned small cigars at two thirds the harm of cigarettes. For both these products the bulk of the 
harm came from morbidity and mortality areas such as cancer, respiratory and cardiovascular disease, followed by Economic cost, Injury and Dependence. There was a big drop in harm from small cigars (67\% of maximum relative harm, MRH) to pipes $22 \%$. Within the tobacco products there was a gradual reduction in harm from water pipe, smokeless unrefined, smokeless refined to snus that has $5 \%$ of MRH. Among the purer non-tobacco vehicle products ENDS were rated to have only $4 \%$ of $\mathrm{MRH}$ and for the even purer NRTs the MRH was only rated at about $2 \%$. Thus there is wide variability in harm among the combustible tobacco-based products, from cigarettes $(100 \%)$ to water pipe (14\%) and even more within the tobacco-based category, from cigarettes (100\%) to snus (5\%). Not surprisingly the purest products, NRTs, with few other ingredients than nicotine were the least harmful and pose little risk for intrinsic harm when used for the treatment of tobacco dependence. Indeed their use would bring significant benefits not just to users but also to non-smokers and society as a whole.

Clearly this exercise speaks to a continuum of harm from nicotine-containing products with cigarettes at one end and NRT products at the other end. The differences between the products are substantial and if policy actions could help to switch use away from cigarettes and other smoked products to purer nicotine products, such as NRT products, massive public health gains would occur.

There is also some evidence that the cigarettes are the most dependence-forming product and products with less harm also may be less dependence-forming [9]. An analogue can be found with alcohol where most countries have policies that steer consumption as much as possible to alcohol-containing beverages with a low alcohol content.

A limitation of this study is the lack of hard evidence for the harms of most products on most of the criteria. That is why we adopted the decision conferencing process: the group of experts worked face-to-face in a peerreview setting with impartial facilitation, sharing relevant data, knowledge and experience to ensure that all perspectives were heard. It is the combination of impartial facilitation, modelling (in this case, MCDA), and information technology (projecting the MCDA model for the group to observe as it was constructed and explored) that enables a group to outperform its members, thus providing the best collective expertise of the experts [28]. Another weakness might be the kind of sample of experts. There was no formal criterion for the recruitment of the experts although care was taken to have raters from many different disciplines.

Even if data were available for all the harms of all the products on all the criteria, judgements would still be required to assess swing-weights. While the magnitude of harm of the most harmful product on each criterion can be informed by data, how much that worst-best difference matters requires an act of judgement. In this way, MCDA separates matters of fact from value judgements. As value judgements are at the heart of political debate, it might be instructive to engage in a public consultation exercise to allow different constituencies to express their views about the weights. This could be a first step in initiating a structured deliberative discourse about nicotinecontaining products, as the politicians, the law and the public might weight the harm criteria differently [29]. In addition, including the benefits of using nicotine products along with the harmful criteria might provide insights into the nature of the benefit-harm balance.

The results of this study suggest that of all nicotinecontaining products, cigarettes (and small cigars in the USA) are very much the most harmful. Interventions to reduce this pre-eminence are likely to bring significant benefits not just to users but also to non-smokers and society as a whole. Attempts to use other forms of nicotine such as ENDS and NRT to reduce cigarette smoking should be encouraged as the harms of these products are much lower.

\section{Acknowledgement}

The authors would like to thank Euroswiss Health (Switzerland) for funding and LIAF (Lega Italiana Anti Fumo) for supporting this research.

\section{Disclosure Statement}

The sponsor of the study had no role in any stage of the MCDA process or in the writing of this article, and was not present at the workshop. All authors had full access to all the data in the study, and had final responsibility for the decision to submit for publication.

K.F. has served as a consultant for most companies with an interest in tobacco dependence treatments. J.F. has served as a consultant to manufacturers of smoking cessation products (e.g. Pfizer, GSK, J \& J, Novartis) and has received a research grant from Pfizer. R.P. has received lecture fees from Pfizer and GSK, a research grant from Pfizer, and he has served as a consultant for Pfizer, Global Health Alliance for treatment of tobacco dependence, and Arbi Group Srl., an e-cigarette distributor. All other authors have no conflicts of interest to declare. 


\section{References}

1 Warner KE: The role of research in international tobacco control. Am J Public Health 2005;95:976-984

2 WHO Report on the Global Tobacco Epidemic, 2013. http://apps.who.int/iris/bitstre am/10665/85380/1/9789241505871_eng. pdf?ua=1. Enforcing bans on tobacco advertising, promotion and sponsorship $\mathrm{WHO} \mathrm{Li}-$ brary Cataloguing-in-Publication Data WHO report on the global tobacco epidemic, 2013. ISBN 9789241505871 (NLM classification: WM 290).

3 Royal College of Physicians: Harm reduction in nicotine addiction: helping people who can't quit. A report by the Tobacco Advisory Group of the Royal College of Physicians. London, RCP, 2007. ISBN 9781860163197.

4 Cahill K, Stevens S, Perera R, Lancaster T: Pharmacological interventions for smoking cessation: an overview and network metaanalysis. Cochrane Database Syst Rev 2013; 5:CD009329.

5 Caggiula AR, Donny EC, Chaudhri N, Perkins KA, Evans-Martin FF, Sved AF: Importance of nonpharmacological factors in nicotine self-administration. Physiol Behav 2002; 77:683-687.

76 Balfour DJ: The neuronal pathways mediating the behavioural and addictive properties of nicotine. Handb Exp Pharmacol 2009;192: 209-233.

7 Fowler JS, Logan J, Wang GJ, Volkow ND: Monoamine oxidase and cigarette smoking. Neurotoxicology 2003;24:75-82.

$>8$ Rose JE: Nicotine and nonnicotine factors in cigarette addiction. Psychopharmacology 2006; 184:274-285.

$>9$ Fagerstrom K, Eissenberg T: Dependence to tobacco and nicotine products: a case for product specific assessment. Nicotine Tob Res 2012; 14:1382-1390.

10 Brennan KA, Crowther A, Putt F, Roper V, Waterhouse U, Truman P: Tobacco particulate matter self-administration in rats: differential effects of tobacco type. Addict Biol 2013, Epub ahead of print.

$>11$ Murray RP, Bailey WC, Daniels K, Bjornson WM, Kurnow K, Connett JE, Nides MA, Kiley JP: Safety of nicotine polacrilex gum used by 3,094 participants in the Lung Health Study. Lung Health Study Research Group. Chest 1996;109:438-445.

12 Stepanov I, Carmella SG, Han S, Pinto A, Strasser AA, Lerman C, Hecht SS: Evidence for endogenous formation of $\mathrm{N}^{\prime}$-nitrosonornicotine in some long-term nicotine patch users. Nicotine Tob Res 2009;11:99-105.
13 Tonini G, D’Onofrio L, Dell'Aquila E, Pezzuto A: New molecular insights in tobacco-induced lung cancer. Future Oncol 2013;9:649-655.

14 Slotkin TA, Lappi SE, Seidler FJ: Impact of fetal nicotine exposure on development of rat brain regions: critical sensitive periods or effects of withdrawal? Brain Res Bull 1993;31: 319-328.

15 Levin ED, Lawrence S, Petro A, Horton K, Seidler FJ, Slotkin TA: Increased nicotine selfadministration following prenatal exposure in female rats. Pharmacol Biochem Behav 2006;85:669-674.

16 England LJ, Kim SY, Tomar SL, Ray CS, Gupta PC, Eissenberg T, Cnattingius S, Bernert JT, Tita AT, Winn DM, Djordjevic MV, Lambe M, Stamilio D, Chipato T, Tolosa JE: Noncigarette tobacco use among women and adverse pregnancy outcomes. Acta Obstet Gynecol Scand 2010;89:454-464.

17 Bruin JE, Gerstein HC, Holloway AC: Longterm consequences of fetal and neonatal nicotine exposure: a critical review. Toxicol Sci 2010;116:364-374.

18 Stepanov I, Yershova K, Carmella S, Upadhyaya $\mathrm{P}$, Hecht SS: Levels of (S)-N'-nitrosonornicotine in U.S. tobacco products. Nicotine Tob Res 2013;15:1305-1310.

19 Leone A: Smoking and hypertension: independent or additive effects to determining vascular damage? Curr Vasc Pharmacol 2011; 9:585-593.

20 Lee PN: Summary of the epidemiological evidence relating snus to health. Regul Toxicol Pharmacol 2011;59:197-214.

21 Ayo-YusufOA, Burns DM: The complexity of 'harm reduction' with smokeless tobacco as an approach to tobacco control in low-income and middle-income countries. Tob Control 2012;21:245-251.

-22 Javed F, Chotai M, Mehmood A, Almas K: Oral mucosal disorders associated with habitual gutka usage: a review. Oral Surg Oral Med Oral Pathol Oral Radiol Endod 2010;109: 857-864.

-23 Maziak W, Ward KD, Afifi Soweid RA, Eissenberg T: Tobacco smoking using a waterpipe: a re-emerging strain in a global epidemic. Tob Control 2004;13:327-333.

24 Cobb CO, Shihadeh A, Weaver MF, Eissenberg T: Waterpipe tobacco smoking and cigarette smoking: a direct comparison of toxicant exposure and subjective effects. Nicotine Tob Res 2011;13:78-87.

25 Saitta D, Ferro GA, Polosa R: Achieving appropriate regulations for electronic cigarettes. Ther Adv Chronic Dis 2014;5:50-61.
26 Dodgson J, Spackman M, Pearman A, Phillips L: Multi-Criteria Analysis: A Manual (2000); ed 2. London, Department for Communities and Local Government, 2009.

27 Nutt DJ, King LA, Phillips LD, Independent Scientific Committee on Drugs: Drug harms in the UK: a multicriteria decision analysis. Lancet 2010;376:1558-1565.

28 Advisory Council on the Misuse of Drugs: Consideration of the Use of Multi-Criteria Decision Analysis in Drug Harm Decision Making. London, Home Office, 2010.

29 Farsalinos KE, Polosa R: Safety evaluation and risk assessment of electronic cigarettes as tobacco cigarette substitutes: a systematic review. Ther Adv Drug Safety 2014;2:67-86.

\section{Editors' Note}

The editors are aware that K.F. has connections with a company that is associated with one of the largest tobacco industries in the world (BAT: Nicoventures), but would like to notice that this standalone company produces smoking cessation products, i.e. electronic cigarettes, that are now in discussion to be regarded as a new form of NRT. NRT is widely accepted as a treatment of patients with tobacco dependence. Therefore, the editors decided that the potential conflict of interest of K.F. should not preclude acceptance and publication of this article. However, the scientific community has to discuss the demarcation between potential conflicts of interest related to companies producing addictive drugs and companies producing therapeutics.
Estimating the Harms of Nicotine-Containing Products
Eur Addict Res 2014;20:218-225

DOI: $10.1159 / 000360220$ 